\title{
EFFECTS OF VITAMIN E AND COENZYME Q10 SUPPLEMENTATION AGAINST DOXORUBICIN-INDUCED NEUROTOXICITY IN RATS
}

\author{
MANAL ABDULKHALIQ IBRAHIM ${ }^{1 *}$, NADA NAJI AL-SHAWI ${ }^{2}$ \\ ${ }^{1}$ Department of Pharmacology and Toxicology, College of Pharmacy, University of Basra, Basra, Iraq. ${ }^{2}$ Department of Pharmacology and \\ Toxicology, College of Pharmacy, University of Baghdad, Baghdad, Iraq. Email: manal.ph2008@yahoo.com
}

Received: 09 June 2018, Revised and Accepted: 09 July 2018

\section{ABSTRACT}

Objective: This work was designed to investigate the effect of Vitamin E and the coenzyme Q10(CoQ10) supplementation on neurotoxicity induced by doxorubicin (Dox) in rats.

Methods: Forty-nine adult Albino rats of both sexes were utilized in this study; animals were randomly enrolled into seven groups of seven animals each. Group I: Control (rats administered corn oil); Group II: Vitamin E at a dose of $100 \mathrm{mg} / \mathrm{kg} / \mathrm{day}$ for 3 weeks; Group III: CoQ10 at a dose of $50 \mathrm{mg} / \mathrm{kg} /$ day for 3 weeks; Group IV: DOX (2.5 mg/kg) intraperitoneally (IP) injected every other day for 2 weeks; Group V: Vitamin E (100 mg/kg/day) orally administered for 3 weeks prior to a DOX $2.5 \mathrm{mg} / \mathrm{kg}$ IP injected every other day for 2 weeks; Group VI: Co Q10 (50mg/kg/day) for 3 weeks orally-administered prior to a IP dose of Dox $2.5 \mathrm{mg} / \mathrm{kg}$ every other day for 2 weeks. Group VII: Co Q10 (50mg/kg/day), Vitamin E (100mg/kg) for 3 weeks orally-administered prior to a IP dose of Dox $2.5 \mathrm{mg} / \mathrm{kg}$ every other day for 2 weeks. Twenty-four hour after the end of the treatment duration, brain of each animal was excised and part of it to be utilized to prepare homogenate for the estimation of caspase-3 (CASP-3), and the remaining part is used for immunohistochemistry examination and to estimate the percent of apoptotic index by terminal deoxynucleotidyl transferase-mediated deoxyuridine triphosphate nick end labeling (TUNEL) assay.

Results: Vitamin E and CoQ10 significantly $(\mathrm{p}<0.05)$ reduced CASP-3, reduced the percent apoptotic index of TUNEL-assay, and there was an improvement in the immunohistochemistry of rats' brain in Groups V, Group VI, and group VII by reducing number of apoptotic cells compared to Group IV.

Conclusion: Both Vitamin E and CoQ10 may have a protective effect against Dox-induced neurotoxicity in rats.

Keywords: Vitamin E, Coenzyme Q10, Doxorubicin, Neurotoxicity, TUNEL-assay, caspase-3.

(C) 2018 The Authors. Published by Innovare Academic Sciences Pvt Ltd. This is an open access article under the CC BY license (http://creativecommons. org/licenses/by/4. 0/) DOI: http://dx.doi.org/10.22159/ajpcr.2018.v11i9.27851

\section{INTRODUCTION}

Cancer is considered as a serious global health problem that is expected to grow rapidly in the next few years, due mainly to unhealthy lifestyles and environmental carcinogens [1]. According to the International Agency for Research on Cancer in 2002, an estimated 11 million people were diagnosed with cancer and 7 million died from malignant disease [2].

Early diagnosis, health care, and developments of various therapies have resulted in a significant improvement of cancer survival, being estimated that up to two-third of cancer has been eventually cured, with striking differences among tumors [3]. For almost a century, systemic therapy of cancer has been dominated by the use of cytotoxic chemotherapeutics. Most of these drugs are DNA-damaging agents that were designed to damage or inhibit rapidly dividing cells [4].

Anthracyclines, including doxorubicin (DOX), are the most efficacious anticancer drugs available; their use has extended over three decades despite numerous adverse effects [5]; where it is widely used for the treatment of human's solid tumors by blocking the process of replication in the malignant cells [6].

The clinical use of DOX can be compromised by the development of life-threatening adverse effects, such as myelosuppression, fatigue, and cognitive impairments [7]. In addition, it has been revealed that chemotherapeutic agents, including DOX, are responsible for brain tissue injury. The neurobehavioral changes induced by DOX have been indicated by authors through the utilization of rodent models [8].
Nowadays, it is well documented that the central nervous system (CNS) and the immune system (IS) are intimately linked through bidirectional chemical messengers [9]. Importantly, it has been implicated in neurodegenerative diseases that accompany CNS injuries [10]. The authors reported that patients undergoing chemotherapy for breast cancer have consistently shown their depressed mood and decreased interest in surroundings [11].

Vitamin $\mathrm{E}$ is the major chain-breaking antioxidant in the body tissues and is the first line of defense against lipid peroxidation, protecting cell membranes from free radical attacks through its free radical quenching activity. It can protect polyunsaturated fats in cell membranes that are important for membrane structure and function, and increased intake of Vitamin E was reported to enhance immune response [12]. Furthermore, Vitamin E may regulate platelet aggregation by inhibiting the platelet cyclooxygenase (COX) activity, and thus it may decrease the production of prostaglandin. It also has a role in the regulation of protein kinase $\mathrm{C}$ activation [13].

Coenzyme Q10 (CoQ10) in the reduced state is an excellent antioxidant, being able to donate its electrons to free radicals such as the hydroxyl radical thereby breaking the free radical cascade [14]. While in its oxidized state, it can accept electrons from free radicals such as the superoxide radical [15].

The unique free radical scavenging properties of CoQ10 have been led to a variety of clinical studies to assess its efficacy in ameliorating various disease states. A considerable amount of published data 
existed on the effects of oral administration of CoQ10 in improving or preventing various medical conditions as atherosclerosis [16], loss of heart muscle contractility $[17,18]$.

The aim of this study is to investigate the effect of Vitamin E and CoQ10 on DOX-induced neurotoxicity in rats.

\section{METHODS}

\section{Chemicals}

DOX as hydrochloride (50 mg vial) was purchased from EBEWE Pharma, AUSTRIA. Vitamin E (soft gelatin capsule $400 \mathrm{mg}$ ) was purchased from Geltec Private Limited, India, and CoQ10 (soft gelatin capsule $30 \mathrm{mg}$ ) was purchased from Basic nutrition, United Kingdom.

\section{Animals}

Forty-nine healthy adult albino rats of both sexes, 3 months old, weighing 160-250 g were utilized in this study; they were obtained from and maintained in the Animal House of the College of Pharmacy, Baghdad University, under conditions of controlled temperature. The animals were fed commercial pellets and tap water ad libitum throughout the experiment period. The study was approved by the Scientific and the Ethical Committees of the College of Pharmacy/University of Baghdad.

\section{Experimental protocol}

The healthy rats were randomly divided into seven groups ( 7 animals) group) as follows:

Group I - Rats orally administered corn oil ( $1 \mathrm{ml} / \mathrm{kg} /$ day) alone for 3 weeks. This group served as control [19].

Group II - Rats orally administered Vitamin E alone at a dose of $100 \mathrm{mg} / \mathrm{kg} /$ day alone for 3 weeks [19].

Group III - Rats orally administered CoQ10 at a dose of $50 \mathrm{mg} / \mathrm{kg} /$ day alone for 3 weeks [20].

Group IV - Rats intraperitoneally (IP) injected with DOX every other day at a dose of $2.5 \mathrm{mg} / \mathrm{kg}$ for 2 weeks [21].

Group V - Rats orally administered $100 \mathrm{mg} / \mathrm{kg} /$ day Vitamin E for 7 days before starting DOX injection and continued for 2 weeks; where, it administered $1 \mathrm{~h}$ prior to DOX IP injected every other day at a dose of $2.5 \mathrm{mg} / \mathrm{kg}$ [20].

Group VI - Rats orally administered $50 \mathrm{mg} / \mathrm{kg} /$ day CoQ10 for 7 days before starting DOX injection and continued for 2 weeks; where, it administered $1 \mathrm{~h}$ prior to DOX IP injected every other day at a dose of $2.5 \mathrm{mg} / \mathrm{kg}$ [19].

Group VII - Rats orally administered $100 \mathrm{mg} / \mathrm{kg} /$ day Vitamin E and $50 \mathrm{mg} / \mathrm{kg} /$ day CoQ10 for 7 days before starting Dox injection and continued for 2 weeks; where, they were orally administered $1 \mathrm{~h}$ prior to DOX IP injected every other day at a dose of $2.5 \mathrm{mg} / \mathrm{kg}$ [20].

Twenty-four hour after the end of the treatment duration, each animal was euthanized by diethyl ether. After that, the skull of each animal was broke by surgical scissor then the brain was excised for homogenate preparation and part of the brain for immunohistochemistry examination by terminal deoxynucleotidyl transferase-mediated deoxyuridine triphosphate nick end labeling (TUNEL) assay.

Estimation of caspase-3 (CASP-3) in brain homogenate

Rats' brain homogenate was used for the estimation of CASP-3 enzyme activity by using ELISA kit (Elabscience, USA).

\section{Immunohistochemistry examination}

Neurocyte apoptosis was investigated by TUNEL assay. The TUNEL method, which detects fragmentation of DNA in the nucleus during apoptotic cell death in situ, was employed using an apoptosis detection kit (Novus, Biological, USA). The average ratio of the total TUNELpositive neurocyte number was calculated from randomly selected 10 microscopic high-power fields for each rat in all of the groups. This ratio represented the apoptotic index of the sample and it was compared between groups.

\section{Statistical analysis}

Data were expressed as the mean \pm standard error of the mean (SEM). Unpaired Student t-test was used for testing the significant difference between two groups. The statistical significance of the differences among various groups was determined by one-way analysis of variance. Differences were considered statistically significant for $\mathrm{p}<0.05$.

\section{RESULTS}

Effect of Vitamin E and CoQ10 against Dox on Caspase-3 (CASP-3) rats' brain homogenate

Table 1 showed that there were non-significant differences $(p>0.05)$ in CASP-3 activity level in brain tissue homogenate in group of rats orally administered Vitamin E $(100 \mathrm{mg} / \mathrm{kg} /$ day alone for 3 weeks $)$ (Group II) compared to control group (Group I). Mean \pm SEM of CASP-3 levels in brain tissue homogenate were, respectively, $4.9 \pm 0.528$ versus $6.1 \pm 0.794$. In similar fashion, there were non-significant differences $(p>0.05)$ in CASP-3 activity level in brain tissue homogenate in group of rats orally administered CoQ10 (50 mg/kg/day alone for 3 weeks) (Group III) compared to control group (Group I). Mean \pm SEM of CASP-3 levels in brain tissue homogenate were, respectively, $5.5 \pm 0.582$ versus $6.1 \pm 0.794$.

Furthermore, rats IP injected with DOX every other day at a dose of $2.5 \mathrm{mg} / \mathrm{kg}$ for 2 weeks (Group IV) produced significant elevation $(\mathrm{p}<0.05)$ in the level of CASP-3 activity in brain tissue homogenate compared to control group (Group I). Mean \pm SEM of CASP-3 levels in brain tissue homogenate were, respectively, $17.5 \pm 0.601$ versus $6.1 \pm 0.794$ Table 1 .

Moreover, there were significant reduction $(\mathrm{p}<0.05)$ in CASP-3 activity level in brain tissue homogenate in groups of rats treated with either $100 \mathrm{mg} / \mathrm{kg} /$ day Vitamin E prior to $2.5 \mathrm{mg} / \mathrm{kg}$ of DOX (Group V), $50 \mathrm{mg} / \mathrm{kg} /$ day CoQ10 prior to $2.5 \mathrm{mg} / \mathrm{kg}$ of DOX (Group VI), or

Table 1: Effects of various treatments on CASP-3 activity levels in rats' brain homogenate and percent (\%) of apoptotic index of TUNEL assay of rats' brain after IP injection of DOX for rat (number of rats=7)

\begin{tabular}{lll}
\hline Group/Treatment & $\begin{array}{l}\text { CASP-3 (pg/ml) for homogenate } \\
\text { of rats' brain (Mean } \pm \text { SEM) }\end{array}$ & $\begin{array}{l}\text { Percent (\%) of apoptotic index } \\
\text { in rats' brain (Mean } \pm \text { SEM) }\end{array}$ \\
\hline Group I/Control/Corn oil & $6.1 \pm 0.794$ & $5.7 \pm 1.6$ \\
Group II/Vitamin E (100 mg/kg/day) & $4.9 \pm 0.528$ & $6 \pm 1$ \\
Group III/Coenzyme Q10 (50 mg/kg/day) & $5.5 \pm 0.582$ & $5.4 \pm 1.06$ \\
Group IV/Doxorubicin (Dox) (2.5 mg/kg) & $17.5 \pm 0.601^{* \mathrm{a}}$ & $62.8 \pm 6.5^{* \mathrm{a}}$ \\
Group V/Vitamin E (100 mg/kg/day) prior to doxorubicin (2.5 mg/kg) & $11.8 \pm 0.877^{\mathrm{bA}}$ & $26.4 \pm 5^{\mathrm{bA}}$ \\
Group VI/Coenzyme Q10 (50 mg/kg/day) prior to doxorubicin & $12.6 \pm 0.986^{\mathrm{cA}}$ & $32 \pm 5^{\mathrm{cA}}$ \\
(2.5 mg/kg) & & $35.2 \pm 5.4^{\mathrm{dA}}$ \\
Group VII/Vitamin E (100 mg/kg/day) and Coenzyme Q10 & $11.3 \pm 0.714^{\mathrm{dA}}$ & \\
(50 mg/kg/day) prior to doxorubicin (2.5 mg/kg) & & \\
\hline
\end{tabular}

(50 $\mathrm{mg} / \mathrm{kg} /$ day) prior to doxorubicin $(2.5 \mathrm{mg} / \mathrm{kg})$

Each value represents mean \pm SEM. $*$ Significantly different $(\mathrm{p}<0.05)$ with respect to the control group. Values with non-identical small letters superscripts $(a, b$, c, and $d)$ are significantly different $(\mathrm{p}<0.05)$ using unpaired Student's t-test. Values with an identical capital letter superscript $(\mathrm{A})$ are non-significantly different ( $>0.05$ )

among (V, VI, and VII) groups using ANOVA. SEM: Standard error of means, CASP-3: Caspase-3, DOX: Doxorubicin, CoQ10: Coenzyme Q10 
$100 \mathrm{mg} / \mathrm{kg} /$ day of Vitamin E and $50 \mathrm{mg} / \mathrm{kg} /$ day of CoQ10 prior to $2.5 \mathrm{mg} / \mathrm{kg}$ of DOX (Group VII) compared to group of rats IP injected with DOX every other day at a dose of $2.5 \mathrm{mg} / \mathrm{kg}$ for 2 weeks (Group IV). Mean \pm SEM of CASP-3 levels in brain tissue homogenate were, respectively, $11.8 \pm 0.877$ versus $17.5 \pm 0.601,12.6 \pm 0.986$ versus $17.5 \pm 0.601$, and $11.3 \pm 0.714$ versus $17.5 \pm 0.601$ [Table 1 ] .

Furthermore, Table 1 showed that there were non-significant differences ( $p>0.05$ ) in CASP-3 activity level in brain tissue homogenate among groups of rats treated with $100 \mathrm{mg} / \mathrm{kg} /$ day Vitamin E prior to $2.5 \mathrm{mg} / \mathrm{kg}$ of DOX (Group V), $50 \mathrm{mg} / \mathrm{kg} /$ day CoQ10 prior to $2.5 \mathrm{mg} / \mathrm{kg}$ of DOX (Group VI), and $100 \mathrm{mg} / \mathrm{kg} /$ day of Vitamin E and $50 \mathrm{mg} / \mathrm{kg} /$ day of CoQ10 prior to $2.5 \mathrm{mg} / \mathrm{kg}$ of DOX (Group VII) compared among each other's.

Effect of Vitamin E and CoQ10 against Dox on percent (\%) apoptotic index TUNEL-assay of rats' brain

Moreover, Table 1 showed that there were non-significant differences $(p>0.05)$ in the percent (\%) of apoptotic cells in brain tissue in group of rats orally administered Vitamin E $(100 \mathrm{mg} / \mathrm{kg} /$ day alone for 3 weeks $)$ (Group II) compared to control group (Group I). Mean \pm SEM of the $\%$ of apoptotic cells in brain tissue were, respectively, $6 \pm 1$ versus $5.7 \pm 1.6$. Similarly, there were non-significant differences $(p>0.05)$ in the $\%$ of apoptotic cells in brain tissue in group of rats orally administered CoQ10 (50 mg/kg/day alone for 3 weeks) (Group III) compared to control group (Group I). Mean \pm SEM of the $\%$ of apoptotic cells in the brain tissue were, respectively, $5.4 \pm 1.06$ versus $5.7 \pm 1.6$.

Besides, a single IP injection of DOX to rats ( $2.5 \mathrm{mg} / \mathrm{kg}$ ) (Group IV) was able to elevate significantly $(\mathrm{p}<0.05)$ the $\%$ of apoptotic cells in rats' brain tissue compared to control/corn oil (Group I) rats. Mean \pm SEM of the $\%$ of apoptotic cells in brain tissue were, respectively, $62.8 \pm 6.5$ and $5.7 \pm 1.6$ [Table 1].

Moreover, there were significant reduction $(\mathrm{p}<0.05)$ in the $\%$ of apoptotic cells in brain tissue in groups of rats treated with either $100 \mathrm{mg} / \mathrm{kg} /$ day Vitamin E prior to $2.5 \mathrm{mg} / \mathrm{kg}$ of DOX (Group V), $50 \mathrm{mg} / \mathrm{kg} /$ day CoQ10 prior to $2.5 \mathrm{mg} / \mathrm{kg}$ of DOX (Group VI), or $100 \mathrm{mg} / \mathrm{kg} /$ day Vitamin E and $50 \mathrm{mg} / \mathrm{kg} /$ day CoQ10 prior to $2.5 \mathrm{mg} / \mathrm{kg}$ of DOX (Group VII) compared to group of rats IP injected with DOX every other day at a dose of $2.5 \mathrm{mg} / \mathrm{kg}$ for 2 weeks (Group IV). Mean \pm SEM of the \% of apoptotic cells in brain tissue were, respectively, $26.4 \pm 5$ versus $62.8 \pm 6.5 ; 32 \pm 5$ versus $62.8 \pm 6.5$; and $35.2 \pm 5.4$ versus $62.8 \pm 6.5$ [Table 1].

Furthermore, Table 1 showed that there were non-significant differences $(p>0.05)$ in the \% of apoptotic cells in brain tissue among groups of rats treated with $100 \mathrm{mg} / \mathrm{kg} /$ day Vitamin E prior to $2.5 \mathrm{mg} / \mathrm{kg}$ of DOX (Group V), $50 \mathrm{mg} / \mathrm{kg} /$ day CoQ10 prior to $2.5 \mathrm{mg} / \mathrm{kg}$ of DOX (Group VI), and $100 \mathrm{mg} / \mathrm{kg} /$ day Vitamin E and $50 \mathrm{mg} / \mathrm{kg} /$ day CoQ10 prior to $2.5 \mathrm{mg} / \mathrm{kg}$ of DOX (Group VII) compared among each other's.
Immunohistochemistry examination (TUNEL assay) in rats' brain tissue

In sections of brain tissues of rats orally administered corn oil (1 ml $/ \mathrm{kg} /$ day) (Group I), Vitamin E $(100 \mathrm{mg} / \mathrm{kg} /$ day) (Group II), and -CoQ10 (50 mg/kg/day) (Group III) each for 3 week showed normal neurocytes (not apoptotic, green-colored cells) as shown in Fig. 1a-c, respectively.

Immunohistochemistry changes in the brain of rats IP injected with DOX $(2.5 \mathrm{mg} / \mathrm{kg})$ every other days for 2 weeks (Group IV) were characterized by the presence of apoptotic cells (brown-colored cells) as shown in Fig. 1d.

Sections of rats' brain orally administered $100 \mathrm{mg} / \mathrm{kg} /$ day of Vitamin E for 3 weeks prior to IP dose of DOX $(2.5 \mathrm{mg} / \mathrm{kg})$ for every other day for 2 weeks (Group V) showed low number of apoptotic cells (browncolored cells) and increased number of normal neurocyte cells (greencolored cells) Fig. 1e.

Besides, brain section of animals orally administered CoQ10 at a dose of $50 \mathrm{mg} / \mathrm{kg} /$ day for 3 weeks prior to IP injection of DOX ( $2.5 \mathrm{mg} / \mathrm{kg}$ ) every other day for 2 weeks (Group VI) revealed low number of apoptotic cells (brown-colored cells) and increased number of normal neurocyte cells (green-colored cells) Fig. 1f.

As well as, brain section of animals orally administered combination of Vitamin E (100 mg/kg/day) and CoQ10 (50 mg/kg/day) for 3 weeks prior to IP injection of DOX every other day for 2 weeks at dose $(2.5 \mathrm{mg} / \mathrm{kg}$ ) (Group VII) observed low number of apoptotic cells (brown-colored cells) and increased number of normal neurocyte cells (green-colored cells) as shown in Fig. 1g.

\section{DISCUSSION}

Toxicity is the major factor hindering DOX treatment. The impairment of neurogenesis and increased neural apoptosis in brain regions was demonstrated by authors [22]. It was found that administration of DOX can induce a peripheral increase in the cytokine tumor necrosis factoralpha (TNF- $\alpha$ ), which may migrate cross the blood-brain barrier and may, in turn, induce several inflammatory pathways, including glial cell activation that can result in more TNF- $\alpha$ production which can cause mitochondrial impairment. The TNF- $\alpha$-induced mitochondrial dysfunction by its downstream consequences, resulting in further increase in oxidative stress cytochrome c release, CASP-3 activity, and TUNEL-positive cell death of all which are suggestive of apoptotic of brain cells following DOX treatment [21].

The current study revealed that DOX-induced neurotoxicity with statistically significant $(\mathrm{p}<0.05)$ elevation in homogenate activity

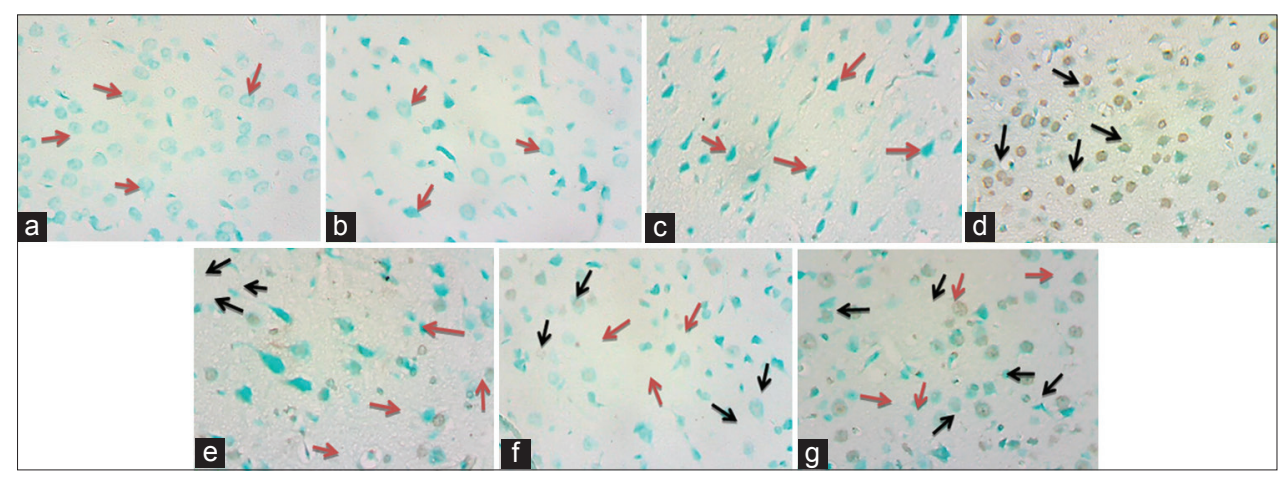

Fig. 1: Immunohistochemistry section of the brain in various experimental rats' groups; (TUNEL assay; ×40). (a) Group I (control (corn oil); (b) Group II (Vitamin E 100 mg/kg); (c) Group III (CoQ10 50 mg/kg); (d) Group IV (doxorubicin [DoX] 2.5 mg/kg); (e) Group V (Vitamin E $100 \mathrm{mg} / \mathrm{kg} /$ day prior to a intraperitoneally [IP] dose of DOX $2.5 \mathrm{mg} / \mathrm{kg}$; (f) Group VI (CoQ10 $50 \mathrm{mg} / \mathrm{kg} / \mathrm{day}$ prior to IP dose of DOX $2.5 \mathrm{mg} / \mathrm{kg}$ ); (g) Group VII (Vitamin E $100 \mathrm{mg} / \mathrm{kg} /$ day and CoQ10 $50 \mathrm{mg} / \mathrm{kg} /$ day prior to IP dose of DOX $2.5 \mathrm{mg} / \mathrm{kg}$ ). Normal neurocyte cells had green color referred by red arrow and apoptotic cells had brown color referred by black arrow 
levels of CASP-3 (Table 1) and significant $(\mathrm{p}<0.05)$ increase in the $\%$ of apoptotic index with respect to negative control group as shown in Table 1.

Investigators demonstrated that mechanisms underlying Vitamin E amelioration neurotoxicity appeared to be related to modulation of aspects of the apoptosis cascade, including reversal of drug-induced increased expression of tumor-suppression factor p53, and the attenuation of neurotoxicity-mediated dysregulation of the critical ratio of Bax to Bcl-2 and Bcl-xl [23]. Moreover, evidence suggested that the alterations in apoptosis-related proteins detected following antioxidant treatment may involve an effect on protein degradation rather than transcription, since in at least one study, while Bcl-2related protein levels were altered following antioxidant treatment [24]; furthermore, it has been demonstrated that Vitamin E (tocopherol) may exert the protective effects that may relate at least in part to the antioxidant capacity of this molecule and its capacity to protect membrane integrity. Furthermore, in cerebellar granule cells grown in vitro, such vitamin may inhibit neurotoxicity-mediated activation of CASP-3 and may diminish the cellular membrane disruption [25].

In the present study, Vitamin $\mathrm{E}$ administered at a dose of $100 \mathrm{mg} / \mathrm{kg} /$ day, prior to IP dose of DOX $2.5 \mathrm{mg} / \mathrm{kg}$ (Group V), significantly $(\mathrm{p}<0.05)$ lowered activity level of CASP-3 compared to DOX-treated rats (Group IV) as shown in Table 1; at the same time, Vitamin E administered at a dose of $100 \mathrm{mg} / \mathrm{kg} /$ day, prior to IP dose of DOX $2.5 \mathrm{mg} / \mathrm{kg}$ (Group V); there was statistically significant $(\mathrm{p}<0.05)$ reduction in the \% of apoptotic index of TUNEL assay as showed in Table 1 when compared with rats IP injected with DOX (Group IV).

Authors reported that treatment with CoQ10 reduced necrotic neuronal cells, and it has significant neuroprotection properties against neuronal damage in neurodegenerative disorders [26]. Furthermore, others showed that CoQ10 may prevent the accumulation reactive oxygen species, improve the mitochondrial membrane potential, inhibit apoptosis-induced factors, and reduce cell death [27]. Besides, pretreatment with CoQ10 in a model of spinal cord contusion improved neurological functions and retention of normal motor neurons [28].

Moreover, in the present study, CoQ10 orally administered at a dose of $50 \mathrm{mg} / \mathrm{kg} /$ day prior to IP dose of DOX $2.5 \mathrm{mg} / \mathrm{kg}$ (Group VI), significantly $(\mathrm{p}<0.05)$ lowered the activity level of CASP-3 and the percent (\%) of apoptotic index of TUNEL assay compared to DOXtreated rats (Group IV) (Table 1).

Furthermore, in the current study, combination of Vitamin $\mathrm{E}$ and CoQ10 administered at a dose of $100 \mathrm{mg} / \mathrm{kg} /$ day and $50 \mathrm{mg} / \mathrm{kg} /$ day, respectively, prior to IP dose of DOX $2.5 \mathrm{mg} / \mathrm{kg}$ (Group VII), significantly $(p<0.05)$ lowered the activity level of CASP-3 and the percent $(\%)$ of apoptotic index of TUNEL assay compared to DOX-treated rats (Group IV) (Table 1).

Moreover, it can be observed from this study that there was an improvement in the immunohistochemistry of TUNEL assay in group of rats treated with Vitamin E alone (Group V), CoQ10 alone (Group VI), or in combination(Group VII) (Fig. 1e-g, respectively); where, reduction in apoptotic cells which had brown-colored and increase number of nonapoptotic cells that had green color when compared to DOX-treated rats (Group IV) (Fig. 1d).

\section{CONCLUSION}

Vitamin E and CoQ10 may have protective effect against DOXinduced neurotoxicity in rats. To the best of our knowledge, this is the first study that examines the effects of Vitamin E and CoQ10 at doses $100 \mathrm{mg} / \mathrm{kg} /$ day, and $50 \mathrm{mg} / \mathrm{kg} /$ day, respectively each, and in combination prior to DOX on rats' brain. Therefore, we did not have a thorough chance to compare the results of this study with other reports.

\section{ACKNOWLEDGMENTS}

This article was abstracted from the PhD Thesis submitted to the Department of Pharmacology and Toxicology, College of Pharmacy, University of Baghdad. The authors gratefully thank the Department of Pharmacology and Toxicology, College of Pharmacy, Baghdad University, and the staff of the College of Veterinary Medicine, Basra University.

\section{CONFLICTS OF INTERESTS}

the authors declare that there is no conflict interest regarding publication of this article.

\section{AUTHORS' CONTRIBUTION}

Manal Abdulkhaliq Ibrahim has provided the design, protocol for conducting experiment, and majority performed experiment in laboratory. Nada Naji Al-Shawi is supervisor for this protocol, give instruction for this design, parameter that suitable and give resolution for any problem.

\section{REFERENCES}

1. Sener SF, Grey N. The global burden of cancer. J Surg Oncol 2005;92:1-3

2. Parkin DM, Bray F, Ferlay J, Pisani P. Global cancer statistics, 2002. CA Cancer J Clin 2005;55:74-108.

3. Urruticoechea A, Alemany R, Balart J, Villanueva A, Viñals F, Capellá G, et al. Recent advances in cancer therapy: An overview. Curr Pharm Des 2010;16:3-10.

4. Kerbel RS, Kamen BA. The anti-angiogenic basis of metronomic chemotherapy. Nat Rev Cancer 2004;4:423-36.

5. Maria A. Mitry, John G. Doxorubicin induced heart failure: Phenotype and molecular mechanisms.IJC Heart Vasc 2016;10:17-24.

6. Cutts SM, Swift LP, Rephaeli A, Nudelman A, Phillips DR. Sequence specificity of adriamycin-DNA adducts in human tumor cells. Mol Cancer Ther 2003;2:661-70.

7. Jansen CE, Dodd MJ, Miaskowski CA, Dowling GA, Kramer J. Preliminary results of a longitudinal study of changes in cognitive function in breast cancer patients undergoing chemotherapy with doxorubicin and cyclophosphamide. Psychooncology 2008;17:1189-95.

8. Merzoug S, Toumi ML, Boukhris N, Baudin B, Tahraoui A. Adriamycinrelated anxiety-like behavior, brain oxidative stress and myelotoxicity in male wistar rats. Pharmacol Biochem Behav 2011;99:639-47.

9. Banks WA, Erickson MA. The blood-brain barrier and immune function and dysfunction. Neurobiol Dis 2010;37:26-32.

10. Kipnis J, Derecki NC, Yang C, Scrable H. Immunity and cognition: What do age-related dementia, HIV-dementia and "chemo-brain" have in common? Trends Immunol 2008;29:455-63.

11. Schlatter MC, Cameron LD. Emotional suppression tendencies as predictors of symptoms, mood, and coping appraisals during AC chemotherapy for breast cancer treatment. Ann Behav Med 2010;40:15-29.

12. Packer L, Weber SU, Rimbach G. Molecular aspects of alpha-tocotrienol antioxidant action and cell signalling. J Nutr 2001;131:369S-73S.

13. Imounan F, Bouslam N, Aasfara J, Alaoui KE, Regragui W, Haddou EA, et al Vitamin $\mathrm{E}$ in ataxia and neurodegenerative diseases: A review. World J Neurosci 2012;2:217-22.

14. Crane FL. Biochemical functions of coenzyme Q10. J Am Coll Nutr 2001;20:591-8.

15. Overvad K, Diamant B, Holm L, Holmer G, Mortensen SA, Stender S, et al. Coenzyme Q10 in health and disease. Eur J Clin Nutr 1999;53:764-70.

16. Chapidze G, Kapanadze S, Dolidze N, Bachutashvili Z, Latsabidze N. Prevention of coronary atherosclerosis by the use of combination therapy with antioxidant coenzyme Q10 and statins. Georgian Med News 2005;118:20-5.

17. Rosenfeldt F, Hilton D, Pepe S, Krum H. Systematic review of effect of coenzyme Q10 in physical exercise, hypertension and heart failure. Biofactors 2003;18:91-100.

18. Sarter B. Coenzyme Q10 and cardiovascular disease: A review. J Cardiovasc Nurs 2002;16:9-20.

19. Galal MK, Khalaf AA, Ogaly HA, Ibrahim MA. Vitamin E attenuates neurotoxicity induced by deltamethrin in rats. BMC Complement Altern Med 2014;14:458

20. Kandhare A, Ghosh P, Ghule A, Bodhankar S. Elucidation of 
molecular mechanism involved in neuroprotective effect of coenzyme Q10 in alcohol-induced neuropathic pain. Fundam Clin Pharmacol 2013;27:603-22.

21. Mohamed RH, Karam RA, Amer MG. Epicatechin attenuates doxorubicin-induced brain toxicity: Critical role of TNF- $\alpha$, iNOS and NF- $\kappa$ B. Brain Res Bull 2011;86:22-8.

22. Kreisel T, Frank MG, Licht T, Reshef R, Ben-Menachem-Zidon O, Baratta MV, et al. Dynamic microglial alterations underlie stressinduced depressive-like behavior and suppressed neurogenesis. Mol Psychiatry 2014;19:699-709.

23. Post A, Rücker M, Ohl F, Uhr M, Holsboer F, Almeida OF, et al. Mechanisms underlying the protective potential of alphatocopherol (vitamin E) against haloperidol-associated neurotoxicity. Neuropsychopharmacology 2002;26:397-407.

24. Haendeler J, Zeiher AM, Dimmeler S. Vitamin C and E prevent lipopolysaccharide-induced apoptosis in human endothelial cells by modulation of bcl-2 and bax. Eur J Pharmacol 1996;317:407-11.

25. Siler-Marsiglio KI, Shaw G, Heaton MB. Pycnogenol and vitamin E inhibit ethanol-induced apoptosis in rat cerebellar granule cells. J Neurobiol 2004;59:261-71.

26. Tawfik MK. Coenzyme Q10 enhances the anticonvulsant effect of phenytoin in pilocarpine-induced seizures in rats and ameliorates phenytoin-induced cognitive impairment and oxidative stress. Epilepsy Behav 2011;22:671-7.

27. Li H, Chen G, Ma W, Li PA. Water-soluble coenzyme q10 inhibits nuclear translocation of apoptosis inducing factor and cell death caused by mitochondrial complex I inhibition. Int J Mol Sci 2014; 15:13388-400.

28. Hwang JY, Min SW, Jeon YT, Hwang JW, Park SH, Kim JH, et al. Effect of coenzyme Q10 on spinal cord ischemia-reperfusion injury. J Neurosurg Spine 2015;22:432-8. 